\title{
Short-Term Credit Costs and U.S. Entrepreneurship ${ }^{1}$
}

\author{
By \\ Jorge Guzman \\ Columbia University \\ Yupeng Liu \\ Rice University
}

\begin{abstract}
We study how variation in short-term credit costs shapes U.S. entrepreneurship. To do so, we implement identification through heteroskedasticity on a new index of daily U.S. firm formation from 1988 to 2014. A one percentage point increase in the 3-month T-Bill is associated with a $6.4 \%$ drop in the number of new firms founded, and a $3.2 \%$ drop in the quality-adjusted quantity of new firms founded, seven days later. The results are robust to economic policy uncertainty, recession periods, and to multiple heteroskedasticity regimes. The rate of firm formation gets back to baseline six weeks after the shock, and there is no corresponding overcompensation, suggesting the loss is permanent.
\end{abstract}

\footnotetext{
${ }^{1}$ We thank Reid Click, Paul Glasserman, Daniel Lewis, Jose Montiel Olea, Scott Stern, and Sharon Sputz for helpful comments, as well as participants in the Columbia Data Science Day. We also acknowledge the generous support of the Kauffman Foundation to develop this paper. All errors or omissions are our own.

Both authors contributed equally to this project. Author order alphabetical.

Jorge Guzman is an Assistant Professor at Columbia Business School. jag2367@ columbia.edu. Uris Hall, 711. 3022 Broadway. New York, NY. 10027.

Yupeng Liu is a doctoral student at Rice Jones School of Business. yl210@ rice.edu. McNair Hall, Loop Road, Houston, TX. 77005.
} 


\section{Introduction}

In the United States, the Federal Reserve (through the federal funds rate) targets the short-term interest rate with the goal of promoting sound economic and employment growth. Nowhere is the relationship from interest rates to growth assumed more important than in entrepreneurship. Startups account for virtually all employment growth in the U.S. (Haltiwanger et al, 2013), and are the theoretical mechanism through which innovation and reallocation occurs in the economy (Schumpeter, 1942; Aghion and Howitt, 1992; Akcigit and Kerr, 2018). However, there is little empirical evidence on whether and how startup formation responds to changes in interest rates. Does U.S. entrepreneurship change with the short-term interest rate? If so, are the most ambitious projects affected or are they instead the lower quality ones? How long does any negative (or positive) impact last, and is it compensated by future changes in firm entry?

On the one hand, there are several reasons to believe entrepreneurs would respond to a change in interest rates. Empirical evidence shows they are often cash constrained in starting new businesses (Hurst and Lusardi, 2004; Corradin and Popov, 2015), and they increase their entrepreneurial activity when they receive a cash windfall such as an exogenous increase to their housing value (Adelino et al, 2015, 2016) or the sudden liquidity of their existing stock holdings (Stuart and Sorenson, 2003). The balance sheets of startups tend to include significant personal and business credit (Robb and Robinson, 2014), and young firms increase their employment when their working capital requirements drop (Barrot and Nanda, 2020). Besides these direct effects on startups, changes in interest rates also change product demand, personal credit, and potentially optimism. Together, all these effects would predict that a reduction in the short-term credit cost (i.e., a drop in the short-term interest rate) should allow some marginal entrepreneurs to decide to undertake productive 
investments and consequently be more likely to start a company given additionally available financing.

On the other hand, there are also reasons to be more skeptical that short-term changes in credit would be consequential for startup formation. Most entrepreneurship occurs through a series of stages, such as idea generation, planning, and growth, that evolve slowly over time (Gans, Scott, and Stern, 2020). It is not clear that entrepreneurs are actually considering credit costs in their choices, and any change may be too short-lived to impact effective entry. In this view, short term changes in credit rates should not impact the total level of startup formation.

Empirical evidence on the response of U.S. entrepreneurship to interest rates appears to be missing. While existing research has clearly showed the value of improving financing institutions and person-specific capital on entrepreneurial entry, ${ }^{2}$ these institutional changes are substantively different from short-term changes in the cost of capital created by variation in interest rates. Yet, it is indeed this type of short-term credit changes that are usually most relevant to financial decisions, and represent the most common levers for policy makers to activate the economy, and manage the process of economic growth.

In this paper, we provide original estimates on the impact of short-term interest rates on overall quantity and quality of entrepreneurship in the United States. Using a novel index of quality (i.e., growth likelihood) ${ }^{3}$ adjusted daily number U.S. business registrations from 1988 to 2014, we use identification through heteroskedasticity to estimate the impact of

\footnotetext{
${ }^{2}$ A significant amount of work has already documented the broad importance of credit for entrepreneurship. For example, survey data shows that a large portion of startups rely on credit (Robb and Robinson, 2014); difference-in-differences cross-regional studies have demonstrated that improving financing institutions increases firm formation (Kerr and Nanda, 2010; Chatterji and Seamans, 2012; Chava et al, 2013; Cerqueiro et al, 2016; Kirshnan et al, 2015; Guzman, 2020); and studies using unexpected shocks to person-specific capital, such as a housing boom or inheritance, find that additional capital leads to entrepreneurial entry (Hurst and Lusardi, 2004; Adelino et al, 2015, 2016; Corradin and Popov, 2015).

${ }^{3}$ Our index is simply an implementation of the entrepreneurial quality approach in Guzman and Stern (2020). We overview the details of this approach Section 3 and refer the reader to their paper for follow-on detail.
} 
changes in short-term interest rates on entrepreneurship. Consistent with the idea that shortterm credit costs matter, we identify a negative and significant effect of interest rate changes on overall entrepreneurship rates. A one percentage point increase in the U.S. 3-month T-Bill is associated with a drop of $6.4 \%$ in the number of new firms founded seven days later. This reduction lasts six weeks after the shock and there is no corresponding overcompensation, suggesting the loss is permanent. However, highlighting that it is the marginally less valuable projects that are being incorporated, we see our coefficient drop by half when we adjust for measures of firm quality rather than simply the number of firms. These results are stable across different time-periods and robust to an overidentification test using different regimes. In contrast to a view that assumes entrepreneurial entry is only influenced over long periods of time, the quick response we observe in our index (within a week) is consistent with emerging evidence that entrepreneurship responds very quickly to economic shocks, such as the significant changes in both the number and composition of new firms observed immediately after the COVID-19 lockdowns (Fazio et al, 2020; Haltiwanger, 2020).

Before proceeding, we briefly outline our identification approach, since it has not been previously used in entrepreneurship research. Figure 1 documents the heteroskedastic relationship that is the basis of our identification strategy. It plots two measures over time. The first is the running six month standard deviation of the U.S. risk free short-term interest rate (3-month T-Bill). We observe significant variation in this measure - that is, there is heteroskedasticity. The second is the running six month correlation between the interest rate and the log of our daily index of quality-adjusted entrepreneurship, called RECPI, which measures the number of daily firm registration events in that day adjusted for their estimated quality at founding. ${ }^{4}$ There is appreciable

\footnotetext{
${ }^{4}$ This index is built from the underlying data in the Startup Cartography Project (Andrews et al, 2020). The data and construction of this index is explained in detail in Sections III and IV.
} 
comovement between the two indexes. The correlation value between the two is on average slightly positive, potentially driven by unobserved variables that influence both the interest rate and entrepreneurship in the economy. However, when the interest rate varies more substantially, it plays a more significant role in determining outcomes, and the correlation turns more negative. We take advantage of these changes in correlation to identify the effect of interest rates on entrepreneurship.

Intuitively, if we consider the entrepreneurship process as determined by interest rates $i_{t}$, and other unobserved factors $\epsilon_{t}$

$$
E_{t}=\beta i_{t}+\epsilon_{t}
$$

then the role of $i_{t}$ in determining changes in $E_{t}$ is more relevant when there is more variance in $i_{t}$.

Figures $2 \mathrm{~A}$ and $2 \mathrm{~B}$ plot a simulation to show this clearly, using two variance regimes for $i_{t}$, but the same $\beta$ and same $\epsilon_{t}$ across regimes. Figure 2A is a low-interest rate regime. In this regime, the realized observations are scattered all over the place because most of the variance comes from $\epsilon_{t}$. On the other hand, in Figure $2 \mathrm{~B}$, the high variance regime, the role of the interest rate becomes more relevant and the slope of the curve is now traced out. We implement the approach of Rigobon (2003), who shows how one can take advantage of these differences in slope across regimes to back out $\beta$. As long as changes in the variance of other determinants are not too correlated with the variance of interest rates, and $\beta$ is stable across regimes (an assumption that we are able to test) it is identified (Lewis, 2019).

The results in this paper contribute to a range of long-standing literatures that connect credit constraints to entrepreneurship. This includes work directly emphasizing entrepreneurial cash constraints and their impact on the economy (Evans and Leighton, 1989; Evans and Jovanovic, 1989; Holtz-Eakin et al, 1994; Gentry and Hubbard, 2004; 
Blanchflower and Oswald, 1998; see Kerr and Nanda, 2009, for a review), work assessing financing institutions and entrepreneurship (Chatterji and Seamans, 2012; Kerr and Nanda, 2010; Adelino et al 2015, 2016; Corradin and Popov, 2015, Cerqueiro et al, 2016; Guzman, 2020; Barrot and Nanda, 2020), and macroeconomic estimates of the impact of monetary policy in general (Romer and Romer, 1989; Romer and Romer, 2004; Rigobon and Sack, 2004; Coibion, 2012; Gertler and Karadi, 2015; Tenreyro and Thwaites, 2016; Nakamura and Steinsson, 2018).

Vis-à-vis this prior work, the present paper provides at least three contributions. The first, and most important, is that our paper is the first paper to study changes in the high frequency (daily) incidence of firm formation and how contemporaneous variation in financial variables influence it. In particular, we show how variation in a common macro-economic variable, the 3-month T-Bill, indeed influences the entry of new firms, and the heterogeneity across this entry. This evidence provides important information for both macroeconomic financial policy, and microeconomic understanding of the nature of firm formation and credit. Future work on this area is likely to be fruitful.

Second, our paper is also the first to estimate the average treatment effects of financing costs in the U.S. economy as a whole. Whereas prior work had focused on identifying variation in a small portion of the data for convenience (such as those individuals receiving an inheritance), our identification approach instead focuses on the total number of firms in the United States and the way credit influences them. This allows our estimates a much clearer policy application, as well as providing novel evidence consistent with U.S. entrepreneurs, in toto, being cash constrained.

Finally, third, from a data perspective, we introduced a new index of firm formation using business registrations that allows observing the daily variation in new firm registrations. Recent evidence from COVID-19 shows daily variation in firm 
formation can be significant and respond quickly with macroeconomic events (Fazio et al, 2020; Haltiwanger, 2020), yet other potential sources of data (such as tax returns) do not allow the type of time granularity our data does. We suspect our index would also be of inherent value to future work.

The remainder of this paper is structured as follows. In Section II, we explain in more detail the identification through heteroskedasticity approach. In Section III, we explain conceptually our approach to measuring quality, which is simply an implementation of Guzman and Stern (2020). We describe in Section IV our underlying data (state-level business registrations), and explain how it allows us to observe daily variation in firm formation. Section V includes all the empirical results. Finally, Section VI concludes.

\section{Identifying the Entrepreneurship Response Through Heteroskedasticity}

Identification through heteroskedasticity is an identification approach widely used in macroeconomics to model time-series relationships that are co-determined. Consider a general setup for the interdependent relationship between entrepreneurship and interest rates, as in the following VAR model:

$$
\begin{gathered}
i_{t}=\alpha_{0}+\gamma E_{t}+\eta_{t} \\
E_{t}=\alpha_{1}+\beta i_{t}+\epsilon_{t}
\end{gathered}
$$

Where $i_{t}$ is the interest rate, $E_{t}$ is the index of entrepreneurship, $\alpha_{0}$ and $\alpha_{1}$ are constants, and $\eta_{t}$ and $\epsilon_{t}$ are macroeconomic shocks that we do not observe but that influence the interest rate and entrepreneurship, respectively. The variance of $\eta_{t}$ and $\epsilon_{t}$ are $\sigma_{\eta}^{2}$ and $\sigma_{\epsilon}^{2}$.

Usual VAR estimates (including SVAR) impose lag restrictions, such as a lack of contemporaneous effects, that are unrealistic for this setting due to co-determinacy. The heteroskedasticity approach adds flexibility by taking advantage of the fact that changes 
in the variance of variables in a VAR model also change the relative importance of each variable in determining the response. If the independent variable is heteroskedastic, and the underlying parameter stable, then this heteroskedasticity can create enough variation to identify the parameter of interest.

The initial approach is developed in Rigobon (2003), which still continues to be the most common implementation identification through heteroskedasticity. Rigobon (2003) focuses on a two-regime framework, with high and low variance. In Rigobon and Sack (2004), they apply this framework to interest rates to determine their impact on asset prices. Our paper is mostly based on this setup, using entrepreneurship rather than asset prices as the outcome variable. ${ }^{5}$

To begin to understand how one might extract $\beta$, we take another look at Figures 2A and 2B. These figures are two simulations of the VAR model (assuming $\alpha_{0}, \alpha_{1}$, and $\gamma$ as zero for simplicity). Both figures have the same values of $\sigma_{\epsilon}^{2}=2$ and $\beta=-0.5$, but we change the variance of the interest rate, $\sigma_{i}^{2}$, across figures to create heteroskedasticity. Figure 2A, representing a low variance regime, has $\sigma_{i}^{2}=2$, while Figure $2 \mathrm{~B}$ has $\sigma_{i}^{2}=5$. While $\beta$ has the same value under both regimes, the change in $\sigma_{i}^{2}$ changes how much the entrepreneurship response is determined by $i_{t}$ versus its idiosyncratic component $\epsilon_{t}$. Figure $2 \mathrm{~A}$ has mostly idiosyncratic variation (from $\epsilon_{t}$ ), while Figure $2 \mathrm{~B}$ traces out the entrepreneurship response. Rigobon (2003) provides a formalization of how to use these changes in information to recover $\beta$.

Specifically, suppose there are two regimes of $\sigma_{\eta}^{2}$, high volatility and low volatility, indexed by $s \in\{1,2\} . \beta$ and $\gamma$ are stable across these two regimes (an assumption that will be tested). The covariance matrix $\widehat{\Omega}_{s}$ for each regime is defined by:

\footnotetext{
${ }^{5}$ We do not include the follow-on improvements by Lewbel (2012), who moved to a continuous number of regimes. Our analysis, however, does include the important identification improvements in Lewis (2019).
} 


$$
\widehat{\Omega}_{s}=\left[\begin{array}{cc}
\omega_{11, s} & \omega_{12, s} \\
\cdot & \omega_{22, s}
\end{array}\right]
$$

Which can be re-stated as

$$
\widehat{\Omega}_{s}=\frac{1}{(1-\gamma \beta)^{2}}\left[\begin{array}{cc}
\beta^{2} \sigma_{\eta, S}^{2}+\sigma_{\epsilon, S}^{2} & \beta^{2} \sigma_{\eta, S}^{2}+\gamma \sigma_{\epsilon, S}^{2} \\
\cdot & \sigma_{\eta, S}^{2}+\gamma^{2} \sigma_{\epsilon, s}^{2}
\end{array}\right]
$$

There are six unknowns in this system $\left(\gamma, \beta, \sigma_{\eta, 1}^{2}, \sigma_{\epsilon, 1}^{2}, \sigma_{\eta, 2}^{2}\right.$ and $\left.\sigma_{\epsilon, 2}^{2}\right)$ and two covariance matrices. This provides six equations which can be solved as long as the matrix is non-degenerate.

Then, $\beta$ is solved by

$$
\beta=\frac{\omega_{12, s}-\gamma \omega_{11, s}}{\omega_{22, s}-\gamma \omega_{12, s}}
$$

And, after some algebra, ${ }^{6} \gamma$ is the solution to the following quadratic:

$$
\left[\omega_{11,1} \omega_{12,2}-\omega_{12,1} \omega_{11,2}\right] \gamma^{2}-\left[\omega_{11,1} \omega_{22,2}-\omega_{22,1} \omega_{11,2}\right] \gamma+\left[\omega_{12,1} \omega_{22,2}-\omega_{22,1} \omega_{12,2}\right]=0
$$

There are two solutions to this equation. One is $\gamma, \beta$ and the other is $\gamma^{*}=$ $1 / \beta, \beta^{*}=1 / \gamma$, reflecting the two ways that the system can be solved.

\section{Measuring the Quality and Quantity of Entrepreneurship}

We next proceed to describe a general approach to measuring our outcome variable - U.S. quality-adjusted entrepreneurship. This approach borrows directly from Guzman and Stern $(2015,2017,2020)$; therefore, what follows is simply an abridged re-statement of this prior work. ${ }^{7}$ We refer the reader to the cited papers for more detail.

\footnotetext{
${ }^{6}$ These derivations are direct copies of Rigobon (2003); we refer the reader to this paper for the algebraic details.

7 This section draws partially from Guzman and Stern $(2015,2017,2020)$, where these measurement statistics are originally introduced.
} 
Guzman and Stern propose a method to estimate quality using predictive analytics and business registration records by combining three interrelated insights. First, because the challenges to reaching a growth outcome as a sole proprietorship are formidable, a practical requirement for any entrepreneur to achieve growth is business registration (as a corporation, partnership, or limited liability company). This practical requirement allows for the formation of a population sample of entrepreneurs "at risk" of growth at a similar (and foundational) stage of the entrepreneurial process. Second, it is possible to potentially distinguish among business registrants through the measurement of founding choices observable at or close to the time of registration. For example, we can measure start-up characteristics (which result from the initial entrepreneurial choices in our model) such as whether the founders name the firm after themselves (eponymy), whether the firm is organized in order to facilitate equity financing (e.g., registering as a corporation or in Delaware), and whether the firm seeks intellectual property protection (e.g., a patent or trademark). Third, though rare, there exist meaningful growth outcomes (such as achieving an IPO or high-value acquisition) for some firms. Combining these insights, we estimate entrepreneurial quality by estimating the relationship between observed growth outcomes and start-up characteristics.

That is, for a firm $i$, born at time $t$, with at-birth start-up characteristics $K_{i, t}$, we observe growth outcome $g_{i, t+s} s$ years after founding and estimate:

$$
\theta_{i, t}=P\left(g_{i, t+s} \mid K_{i, t}\right)=f\left(\alpha+\beta K_{i, t}\right)
$$

and we use the predicted value of this regression as our measure of entrepreneurial quality. As long as the process by which start-up characteristics map to growth remains stable over time (an assumption that appears valid in the $\mathrm{data}^{8}$ ), this mapping allows us to form an

\footnotetext{
${ }^{8}$ See Appendix Table B2 of Guzman and Stern (2020).
} 
estimate of entrepreneurial quality from founding characteristics for any business registrant within our sample.

We use these estimates to generate two entrepreneurship statistics proposed by Guzman and Stern that capture the level of entrepreneurial quality, quantity, and quality adjusted quantity for a given set of startups founded on a specific day.

The Entrepreneurial Quality Index (EQI). To create an index of entrepreneurial quality for any group of firms we simply take the average quality of firms founded in a day.

$$
E Q I_{t}=\frac{1}{N_{t}} \sum_{i \in\left\{I_{t}\right\}} \theta_{i, t}
$$

where $\left\{I_{t}\right\}$ represents the set of all firms in time period $t$, and $N_{t}$ represents the number of firms in $t$.

The Regional Entrepreneurship Cohort Potential Index (RECPI). The overall inherent potential for a cohort of startups combines both the quality of entrepreneurship and the number of firms (a measure of quantity). To do so, we define RECPI as simply EQI multiplied by the number of firms founded on that day:

$$
R E C P I_{t}=E Q I_{t} \times N_{t}
$$

Since our index multiplies the average probability of a firm in $t$ to achieve growth (quality) by the number of firms, it is, by definition, the expected number of growth events from a cohort given the startup characteristics of that group. This measure of course abstracts away from the ability to realize the performance of startups founded within a given cohort, and instead can be interpreted as a measure of the "potential" of a cohort given the "intrinsic" quality of firms at birth. Together, EQI and RECPI offer researchers the ability to undertake detailed evaluations of entrepreneurial quality and quality-adjusted quantity over time. 


\section{Data Overview: Measuring Daily New Entrepreneurship in the U.S.}

Building on the entrepreneurial quality approach, a key data innovation of our paper is to use it to develop a daily measure of U.S. entrepreneurship based on firm founding events and their characteristics at founding. This section describes how our daily index is developed. The index may be of research interest in its own right, as it is the first measure of U.S. firm formation that provides time granularity at the level of daily frequency.Business Registration Records and Entrepreneurial Quality Estimates

Our U.S. daily index of entrepreneurship is built from business registration records collected as part of a broader effort for the Startup Cartography Project (Andrews et al, 2020). Business registration is the act of formally creating a legal entity - a corporation, partnership, or LLC — with which to conduct business. We record 35 million registrations, accounting for all firms registered between 1988 and 2014 in the District of Columbia and 49 U.S. states, ${ }^{9}$ representing $99.6 \%$ of all U.S. economic activity. ${ }^{10} \mathrm{We}$ limit our sample to the set that is either (a) a for-profit firm in the local jurisdiction or (b) a for-profit firm whose jurisdiction is Delaware but whose principal office address is in the local state. Our analysis therefore excludes non-profit organizations as well as companies whose primary location is not in the state. This data construction is explained in detail in Guzman and Stern (2020), and versions of this data are also used in Guzman and Stern (2015, 2017), Fazio et al (2019), Guzman (2018), Catalini et al (2019a, 2019b), and others.

As in that prior work, for each observation, we construct variables related to: (i) growth outcomes (IPO or significant acquisition); (ii) firm characteristics based on business

\footnotetext{
${ }^{9} \mathrm{We}$ are unable to include local firms in Delaware (i.e. those actually doing business locally in the state) because Delaware jurisdiction plays an important, and unique, role for corporate governance choices for all firms in the United States. It is important to highlight that we do include (and take advantage of) all Delaware jurisdiction companies registered as doing business activity in any state outside Delaware.

${ }^{10}$ Based on the BEA's 2013 state GDP estimates.
} 
registration observables; and (iii) firm characteristics based on external data that can be directly linked to the firm (e.g. patents, trademarks).

i. Growth Outcomes. The growth outcome, Growth, is a dummy variable equal to 1 if the firm has an initial public offering (IPO) or is acquired at a meaningful positive valuation within 6 years of registration as reported in SDC Platinum.

ii. Firm Characteristic Measures Based on Business Registration Data. We first create two binary measures that relate to how the firm is registered: Corporation, which captures whether the firm is a corporation rather than an LLC or partnership, and Delaware, equal to one if the firm is registered in Delaware. We then create five additional measures based directly on the name of the firm. Eponymous is equal to 1 if the first, middle, or last name of the top managers is part of the name of the firm itself. ${ }^{11}$ Our last measure relates to the structure of the firm name. Based on our review of naming patterns of growth-oriented startups versus the full business registration database, a striking feature of growthoriented firms is that the vast majority of their names are at most two words (plus perhaps one additional word to capture the organizational form, e.g. "Inc."). We define Short Name to be equal to one if the entire firm name has three or less words, and zero otherwise. ${ }^{12}$ We then create several measures based on how the firm name reflects the industry or sector within which the firm is operating, taking advantage of the industry categorization of the US Cluster Mapping Project ("US CMP”) (Delgado, Porter, and Stern, 2016) and a text analysis approach. We develop eight such measures. The first three measures are associated with broad

\footnotetext{
${ }^{11}$ Belenzon, Chatterji, and Daley $(2017,2019)$ perform a more detailed analysis of the interaction between eponymy and firm performance, finding an important negative relationship between an intent to use equity financing and eponymy.

${ }^{12}$ Companies such as Akamai or Biogen have sharp and distinctive names, whereas more traditional businesses often have long and descriptive names (e.g., "New England Commercial Realty Advisors, Inc.”).
} 
industry sectors and include whether a firm can be identified as local (Local), traded (Traded) or resource intensive (Resource Intensive). The other five measures capture industry groups in high technology sectors that are typically associated with high growth firms, including whether the firm is within the biotech (Biotech Sector), e-commerce (E-Commerce), other information technology (IT), medical devices (Medical Devices) or semiconductors (Semiconductor) space.

iii. Firm Characteristic Measures Based on External Observables. We also construct two measures related to quality based on data from the U.S. Patent and Trademark Office. Patent is equal to 1 if a firm holds a patent application within the first year and 0 otherwise. We include patents that are filed by the firm within the first year of registration and patents that are assigned to the firm within the first year from another entity (e.g., an inventor or another firm). Our second measure, Trademark, is equal to 1 if a firm applies for trademark protection within a year from registration.

Entrepreneurial Quality Logit Model. We next consider how these founding observables predict follow-on growth. In Table 1, we replicate the analysis in Andrews et al (2020) and report the incidence rate ratios of the coefficients of a logit model on all startups founded between 1988 and 2010, using our binary growth outcome as the dependent variable. The model includes founding state fixed effects and reports robust standard errors. Corporate governance appears important. Startups founded as corporations are $187 \%$ more likely to grow. We also find large effects for the choice of name: firms with a short name are $123 \%$ more likely to grow, while eponymous firms are $71 \%$ less likely to grow. Intellectual property similarly predicts performance. Firms with a trademark at founding are more than 3 times more likely to grow, and those with a patent are 23 times more likely to grow. 
Interestingly, the choice of jurisdiction — whether in a local state or in Delaware — appears to truly influence the probability of growth: firms in Delaware are 16 times more likely to achieve this outcome. These two variables - intellectual property and jurisdiction choice interact. Firms that both have a patent and are registered in Delaware are 93 times more likely to grow. The coefficients for our name-based sector dummies are also significant, though the magnitude appears lower than the effects of corporate form, name, intellectual property, and jurisdiction choice. Bringing all these together, a short-named Delaware corporation with a patent is 500 times more likely to grow than a local LLC. The predicted value of this regression is the estimated entrepreneurial quality of each firm.

We aggregate this estimated quality based on the date of business registration into two daily indexes of entrepreneurship for all business days between 1988 and 2014. ${ }^{13}$ The first measure, $O b s$, is the raw number of observations registered on each date in our data. The second measure, RECPI, is the quality adjusted quantity for each day.

\section{A. Measures of Short-Term Interest Rates.}

Consistent with the literature, we use the 3-month Treasury Bill (T-Bill) Rate as a measure of the short-term interest rate. We downloaded the 3-month T-Bill daily data from the Federal Reserve website ${ }^{14}$ for all business days from 1988 to 2014 . To simplify the interpretation of our estimates, we multiply the rate by 100 so that a one point increase in our measure represents a one percentage point increase in the interest rate.

Summary Statistics. Table 2 shows the summary statistics of our data. We have 6,755 observations. The average day in our data has 5,079 new firm registrations in the United States, with an average quality of 0.001 , and a RECPI of 2.8 . We choose to use

\footnotetext{
${ }^{13}$ Keeping only to business days is necessary for our empirical strategy because the interest rate only changes during business days.

${ }^{14}$ Board of Governors of the Federal Reserve System (US), 3-Month Treasury Bill: Secondary Market Rate [DTB3], retrieved from FRED, Federal Reserve Bank of St. Louis; https://fred.stlouisfed.org/series/DTB3, September 12, 2019.
} 
these measures in their natural log, to allow ease of interpretation of our coefficients as the percentage change of entrepreneurship resulting from an interest rate change. The mean of the $\log (\mathrm{Obs})$ is 8.4 and the mean of $\log (\mathrm{RECPI})$ is 1.0 .

\section{Empirical Results}

We now proceed to the core of our paper, estimating the impact of interest rate changes on U.S. entrepreneurship. We begin our analysis by presenting our main estimates, the impact of the interest rate on firm formation seven days later, using two regimesand low variance in interest rates. We focus on the firms founded seven days later, rather than contemporaneously, to allow some time for the interest rate shock to diffuse in the economy and influence the choices of entrepreneurs. After presenting our main results, we present robustness tests using subsamples to show that our results are not driven by recessionary periods, or by the low inflation period after 2008, and that they remain robust after controlling for measures of economic policy uncertainty. We then split our data across four regimes to create six possible regime pairs, and perform an overidentification test on our estimate by estimating our parameter across each possible pair as in Rigobon and Sack (2004). The estimates, ranging from -.09 to -.025, paint a consistent picture of a negative impact of interest rates on entrepreneurship and confirm the broad stability of our parameter across samples and regimes. Next, we use lags and leads of our dependent variable, both daily and weekly, to assess the threat of pre-trends and dynamics of our estimate across time. We find no pre-trends, suggesting no anticipatory response from entrepreneurs to the shock and indicating that our approach is valid. After an initial drop, we see the flow of entrepreneurship recover after seven weeks, but there is no overshooting response later on to compensate for the prior loss. Finally, for completeness, we replicate our approach using measures of long-term (rather 
than short-term) interest rates as the independent variable, such as the 20-year T-Bill, and the spread between the 20-year and 3-month T-Bills. We find that both of these shocks show pre-trends in our data (entrepreneurs respond before the rate increase); therefore, our approach does not allow us to identify the impact of long-term rates on entrepreneurship.

\section{A. Main Estimates: Two Interest Rate Regimes}

We begin by defining our two variance regimes. For all days in our sample, we estimate the ten-day rolling variance ${ }^{15}$ of the 3 -month T-Bill. We then split the sample based on this variance into a high variance regime (above the mean) and a low variance regime (below the mean). In Table 3, we report the average variance of interest rates, the average ten-day variance of our entrepreneurship indexes, and the average ten-day correlation between the 3-month T-Bill and entrepreneurship under each regime. The distribution of the data is representative of the skewness of the interest rate movements. $82 \%$ of the data is in the low variance regime, while only $18 \%$ of the data is in the high variance regime. The variance of the T-Bill obviously increases from the low to the high variance regime. However, we observe no change in the average variance of $\log (R E C P I)$ or $\log (O b s)$. An unreported regression using a dummy for the regime and interest rates as the dependent variable evaluates the strength of the data for identification through heteroskedasticity. The F-statistic of this regression is $653 .^{16}$

\footnotetext{
${ }^{15}$ While using ten days only allows a few observations with which to estimate the variance, we consider it a cleaner approach as it will only include recent events in its estimate rather than the risk of longer lags.

${ }^{16}$ Lewis (2019) shows that the identification approach can break down if there are proportional increases in the variance of both treatment and outcome. He recommends running a regression with regime dummies on the independent variable to assess the strength of identification when using identification through heteroskedasticity. Specifically, he shows that our problem can also be represented as an instrumental variables problem, where this regression represents the first stage. Lewis suggests using an F-statistic of 37 or higher as a rule of thumb for strong identification.
} 
Table 4 reports our main results. Column (1) is the coefficient from a naïve OLS regression of the interest rate on $\log (R E C P I)$. This estimate is likely biased due to endogeneity. The coefficient is -0.08 . If valid, it would have suggested that a one percentage point increase in the T-Bill rate results in an average $8 \%$ drop in the qualityadjusted quantity of entrepreneurship. Column (2) uses instead identification through heteroskedasticity, reporting the estimate of $\beta$ in 500 bootstrapped samples. The coefficient is much lower, -0.032 , with a 95 -percent confidence interval from -0.075 to 0.011. A one percentage point increase in the interest rate leads to an average drop of $3.2 \%$ in the flow of entrepreneurship, measured seven days later. Figure $3 \mathrm{~A}$ plots a histogram of the estimates across the 500 bootstrap samples for completeness.

We then repeat these estimates with $\log (O b s)$, our quantity measure, as the dependent variable in Columns (3) and (4). Both the OLS and the heteroskedasticity estimates are higher than their RECPI counterparts. The naïve OLS coefficient in Column (3) is -0.141 . The heteroskedasticity estimate in Column (4) has a mean of $-6.4 \%$, and the 95 percent confidence interval ranges from -0.145 to 0.016 . Figure $3 \mathrm{~B}$ presents the histogram of the bootstrapped estimates.

The difference in the coefficients between the quality-adjusted outcome and the quantity outcome provides insight into the relative impact of interest rates across the firm quality distribution. Consistent with a view that higher quality entrepreneurs are also better able to find capital, our evidence suggests that it is the lower quality (less growth oriented) entrepreneurs that appear to be particularly sensitive to changes in the interest rate. Interestingly, these results stand in contrast to other work highlighting the sensitivity of highly innovative ideas to the total supply of capital (Nanda and Rhodes-Kropf, 2013; Rampini, 2004; Bernanke and Gertler, 1989). Understanding the sources of these 
differences — such as the differential role of equity and bank financing in entrepreneurshipis an important question for future work.

\section{B. Robustness Tests: Subperiods, Policy Uncertainty, and Multiple Regimes}

We next perform several tests to assess the robustness of our estimate. We begin in Table 5 by repeating our approach across two different subsamples. Our goal is to evaluate whether our results are sensitive to the exclusion or inclusion of some specific time periods within our data, and if there is enough stability in the estimate of $\beta$ we report. Column (1) reports our main estimate from Table 4 for ease of comparability. Column (2) looks at the two complete business cycles in our data where interest rates have behaved normally, from March 1991 to December 2007. We do this to assess if our estimate is an artifact of the Great Recession and its aftermath, particularly the low interest rate levels during this time period. The estimate of $\beta$ is -0.047 . Though not statistically different from our main estimate, if anything, it suggests that the negative response we document could be a little higher in time periods where the zero lower bound of interest rates do not bind. Column (3) instead uses our full time period but removes the dates that fall within any NBER-dated recession. We do this to evaluate the possibility that the high variance in interest rates is correlated with recessions somehow, and therefore our relationship is not indicative of short-term credit changes, but instead large shocks (as in recessions). The effect remains roughly stable. Together, we interpret these two results as consistent with the idea that the negative relationship between interest rates and entrepreneurship is quite stable across the different economic situations the United States has faced since 1988 (though we recognize that the relationship between our two variables might change over a longer time period). 
In Table 6, we introduce a robustness test where we control for economic policy uncertainty. We do this to consider the possibility that variance in the interest rate is correlated with policy uncertainty, ${ }^{17}$ or that policy uncertainty is a hidden variable driving our estimates. We control for policy uncertainty by regressing $\log (R E C P I)$ on the $\log$ of the US Economic Policy Uncertainty Index released by Baker et al (2016), and then using the residual of this measure as the dependent variable. Our results are virtually unchanged and, if anything, slightly larger and more precise coefficients.

We next look at using multiple regimes. The two regimes used so far allow for a just-identified estimate, but more regimes can allow an overidentification test. We split our sample based on the ten-day rolling variance of $\log (R E C P I)$ into observations above and below its mean, allowing us to create four regimes. Regime 1 has low variance for both the T-Bill rate and RECPI, Regime 2 has high variance for both, Regime 3 has high variance for the T-Bill but low variance for RECPI, and vice versa for Regime 4 . The summary statistics are presented in Table 7. Due to skewness in the variance of our measures, the data is not evenly distributed across these four regimes. Regime 1 accounts for $75 \%$ of all the data, Regime 2 for about $2 \%$, Regime 3 for $16 \%$, and Regime 4 for $7 \%$.

Table 8 presents estimates replicating our approach on each of the six potential pairs that can be created using these four regimes. The results are very consistent across specifications. All specifications have a negative coefficient with confidence intervals that overlap with the confidence interval of our main estimate, except for Column (7) which is slightly more negative. Notwithstanding any small differences, the consistency across the six estimates is considerable. We interpret this evidence to be confirmatory of our main estimate. They suggest a level of stability in the main parameter estimated

\footnotetext{
${ }^{17}$ Bloom et al (2007) uses variance in the stock-market as a measure of uncertainty.
} 
across our data and confirm that entrepreneurs do respond negatively to short-term changes in the interest rate.

\section{Time Dynamics of the Impact of Interest Rates on Entrepreneurship}

Our next step is to consider how our estimate of the impact of interest rate shocks varies based on lagged or lead measures of our outcome. The goal of this analysis is two-fold. First, we would like to assess the possibility of pre-trends in our approach. If the increase in the interest rate is, in fact, a shock, then there should not be an anticipated entrepreneurship response to future interest rate increases. Second, this approach also allows us to document the dynamics of our effect, such as how quickly the negative response in entrepreneurship becomes evident, how long it takes for this difference to return to zero, and whether we see an overshooting later on to compensate for the initial drop in entrepreneurship.

In Figure 4, we report coefficients of our estimate using $\log (R E C P I)$ lagged in weekly intervals. In the pre-period, the estimates are noisy and hover around zero, suggesting that RECPI and the interest rate shock do not have any relationship before the shock occurs. We then observe a negative response the week following the shock, which is greatest two weeks after the shock. This response remains negative, in both the point estimate and in a statistically significant sense for a total of six weeks, and then returns to zero seven weeks later. Afterwards, there is no overcompensating response to regain the entrepreneurship lost in the prior weeks. Instead, the rate remains stable around zero up to the end of the time period we consider. The absence of any positive compensating response later-on suggests the loss is permanent.

We go deeper into the time dynamics in Figure 5 by plotting daily coefficients for the period from 30 days before until 30 days after the interest rate shock. We observe, 
once again, no pre-trend in the data, and, in fact, no contemporaneous response to changes in the 3-month T-Bill. Rather, the effect appears to materialize five days later, after which it reaches the lowest point estimate in day 14 and remains negative afterwards.

\section{Long Term Interest Rates and the Yield Curve}

Finally, for completeness, we report in the appendix tables a replication of our approach that instead uses long-term interest rates as the independent variable. In Table A1 and Figures A1 through A4, we report estimates of changes in the 20-year T-Bill on entrepreneurship, and, separately, estimates of changes in the yield curve (i.e., the difference between the 20-year and the 3-month T-Bill) on entrepreneurship. While the coefficients we estimate are negative and significant, our time-coefficients in this analysis show that there are meaningful pre-trends, including an anticipated response to changes in the interest rate. In the daily coefficients, we see that our approach of estimating the impact of the 20-year T-Bill turns increasingly negative about fourteen days before the interest rate shock. This is surprising and inconsistent with exogeneity. We conclude from this analysis that our approach does not allow us to identify the impact of changes in the 20 year rate on entrepreneurship.

\section{CONCLUSION}

Understanding how variation in short-term interest rates shapes overall U.S. entrepreneurship is an important question for both macro-finance and the microeconomic understanding of entrepreneurship. In this paper, we used a new index of daily business registrations created from the Startup Cartography Project and identification through heteroskedasticity to estimate how the quantity and quality adjusted quantity of 
entrepreneurship respond to shocks in the short-term interest rate. We find that entrepreneurs respond negatively to interest rate shocks, with the negative response being greater for lower quality firms. A 1 percentage point increase in the interest rate predicts a drop of $3.2 \%$ in the flow of quality-adjusted quantity of entrepreneurship seven days later, and a drop of $6.4 \%$ in quantity alone. There are no pre-trends, and the gap lasts about six weeks, after which it returns to zero. Furthermore, we do not observe any overshooting afterward to compensate for the initial drop in entrepreneurship, which suggests that the loss is permanent.

These results attest to the important role of liquidity constraints on entrepreneurship. In interpreting them, however, we must include some caveats. In particular, we focus on a specific margin of business activity that does not fully capture the process of entrepreneurship - business registration. Using the legal filings of companies allows us to observe the incidence of companies, up to a level of daily granularity, at the same foundational moment for each firm (when the entrepreneurs choose to register it). Nonetheless, it is possible that other aspects of entrepreneurship, such as ideation or assembling a team, are not influenced by the interest rates in the same way that the legal founding process is. The key untested assumption in our results is a level of monotonicity between these other processes and legal registration itself.

Moreover, our measure of quality is incomplete and imperfect, and can only partially account for the heterogeneity in firm potential at founding. A natural conclusion of our approach is thus that the difference between the quantity estimate and the quality-adjusted estimate represents a lower bound to the heterogeneity in responses to interest rate shocks.

Finally, our identification approach relied on specific assumptions about the stability of our key parameter across variance regimes. We perform a substantial number 
of robustness tests to assess this stability within our sample, leading us to conclude that it is stable across our time period. Still, changes in the nature of business in the past or in the future could potentially change our underlying estimates.

Ultimately, the way in which liquidity shapes entrepreneurship is a critical question for finance, entrepreneurship, and economic growth, but most of the work so far has focused on sources of variation that do not reflect the interest rate changes that are most common in the economy. In this paper, we estimated the role of changes in the interest rates on entrepreneurship. As finance take a central role in guiding the U.S. economic recovery from the COVID-19 induced recession, our analysis provides timely information on how credit and monetary policy can reactivate entrepreneurship and economic growth.

\section{REFERENCES}

Adelino, Manuel, Antoinette Schoar, and Felipe Severino. (2015). "House Prices, Collateral, and Self-Employment." Journal of Financial Economics 117(2): 288-306.

Adelino, Manuel, Antoinette Schoar, and Felipe Severino. (2016). "Loan Originations and Defaults in the Mortgage Crisis: Further Evidence." Review of Financial Studies 29(7): 1635-70.

Aghion, Philippe and Peter Howitt. (1992). "A Model of Growth through Creative Destruction.” Econometrica 60(2): 323-51.

Akcigit, Ufuk, and William R. Kerr. (2018). "Growth through Heterogeneous Innovations." Journal of Political Economy 126(4): 1374-1443.

Andrews, Raymond J., Catherine Fazio, Jorge Guzman, Yupeng Liu, and Scott Stern. (2020). "The Startup Cartography Project: Measuring and Mapping Entrepreneurial Ecosystems." Working Paper.

Baker, Scott R., Nicholas Bloom, and Steven J. Davis. (2016) "Measuring Economic Policy Uncertainty.” The Quarterly Journal of Economics 131(4): 1593-1636.

Barrot, Jean Noel, and Ramana Nanda. (2020) "The Employment Effects of Faster Payment: Evidence from the Federal Quickpay Reform.” The Journal of Finance. 75 (6): 31393173 
Belenzon, Sharon, Aaron Chatterji, and Brendan Daley. (2017). "Eponymous Entrepreneurs." The American Economic Review 107(6): 1638-55.

Belenzon, Sharon, Aaron Chatterji, and Brendan Daley. (2019). "Choosing Between Growth and Glory". Management Science. Forthcoming.

Bernanke, Ben, and Mark Gertler. (1989). "Agency Costs, Net Worth, and Business Fluctuations," The American Economic Review 79(1): 14-31.

Blanchflower, David, and Andrew Oswald. (1998). "What Make an Entrepreneur?" Journal of Labor Economics 16(1): 26-60.

Bloom, Nick, Stephen Bond, and John Van Reenen. (2007). "Uncertainty and Investment Dynamics." The Review of Economic Studies 74(2): 391-415.

Catalini, Christian, Jorge Guzman, and Scott Stern. (2019a). "Passive Versus Active Growth: Evidence from Founder Choices and Venture Capital Investment." NBER Working Paper \#26073.

Catalini, Christian, Jorge Guzman, and Scott Stern. (2019b). "Hidden in Plain Sight: Venture Growth with or without Venture Capital.” NBER Working Paper \#26521.

Chatterji, Aaron K, and Robert Seamans. (2012). "Entrepreneurial Finance, Credit Cards, and Race.” Journal of Financial Economics 106(1): 182-195.

Chava, Sudheer, and Alexander Oettl, and Ajay Subramanian, and Krishnamurthy Subramanian. (2013). "Banking Deregulation and Innovation." Journal of Financial Economics 109(3): 759-774.

Coibion, Olivier. (2012). “Are the Effects of Monetary Policy Shocks Big or Small?” American Economic Journal: Macroeconomics 4(2): 1-32.

Corradin, Stefano, and Alexander Popov. (2015). "House Prices, Home Equity Borrowing, and Entrepreneurship." The Review of Financial Studies 28(8): 2399-2428.

Cerqueiro, G., Steven Ongena, and Kasper Roszbach. (2016). “Collateralization, Bank Loan Rates, and Monitoring.” The Journal of Finance 71(3): 1295-1322.

Delgado, Mercedes, Michael E. Porter, and Scott Stern. (2016). "Defining clusters of related industries.” Journal of Economic Geography 16(1): 1-38.

Evans, David S., and Boyan Jovanovic. (1989). “An Estimated Model of Entrepreneurial Choice under Liquidity Constraints." Journal of Political Economy 97(4):808-827

Evans, David S., and Linda S. Leighton. (1989). "Some Empirical Aspects of Entrepreneurship.” The American Economic Review 79(3): 519-535.

Fazio, Cathy, Jorge Guzman, and Scott Stern. (2019). "The Impact of State-Level R\&D Tax Credits on the Quantity and Quality of Entrepreneurship." NBER Working Paper \#26099

Fazio, Cathy, Jorge Guzman, and Scott Stern. (2020). "New businesses need a big rescue, too." Forbes. Available at: 
https://www.forbes.com/sites/columbiabusinessschool/2020/04/24/new-business-needsa-big-rescue-too/?sh=7e8c1a56309c

Gans, Joshua S., Erin L. Scott and Scott Stern. (2020). Entrepreneurial Strategy. forthcoming

Guzman, Jorge, and Scott Stern. (2015). "Where is Silicon Valley?" Science 347(6222): 606609.

Guzman, Jorge and Scott Stern. (2017). "Nowcasting and Placecasting Entrepreneurial Quality and Performance." Measuring Entrepreneurial Business: Current Knowledge and Challenges. Chicago, IL: University of Chicago Press.

Guzman, Jorge. (2018). "Go West Young Firm: Agglomeration and Embeddedness in Startup Migrations to Silicon Valley.” SSRN Working Paper \#3175328.

Guzman, Jorge, and Scott Stern. (2020). "The State of American Entrepreneurship: New Estimates of the Quantity and Quality of Entrepreneurship for 32 US States, 1988-2014." American Economic Journal: Economics Policy 12(4): 212-43.

Gentry, William, and R. Glenn Hubbard. (2004). "Entrepreneurship and Household Saving." Advances in Economic Analysis \& Policy 4(1): 1053-1053.

Gertler, Mark, and Peter Karadi. (2015). "Monetary Policy Surprises, Credit Costs, and Economic Activity." American Economic Journal: Macroeconomics 7(1): 44-76

Haltiwanger, John, Ron Jarmin and Javier Miranda. (2013). "Who Creates Jobs? Small Versus Large Versus Young.” Review of Economics and Statistics. 95: 347-361.

Haltiwanger, John (2020), “Applications for new businesses contract sharply in recent weeks: A first look at the weekly Business Formation Statistics”, mimeo, April.

Holtz-Eakin, Douglas, David Joulfaian and Harvey Rosen. (1994). "Entrepreneurial Decisions and Liquidity Constraints.” RAND Journal of Economics 25(2): 334-347.

Hurst, Erik, and Annamaria Lusardi. (2004). "Liquidity Constraints, Household Wealth, and Entrepreneurship.” Journal of Political Economy 112(2):319-347.

Kerr, William R., and Ramana Nanda. (2009). "Democratizing entry: Banking deregulations, financing constraints, and entrepreneurship." Journal of Financial Economics 94(1): 124-149.

Kerr, William R., and Ramana Nanda. (2010). "Banking Regulations, Financing Constraints, and Firm Entry Size." Journal of the European Economic Association 8(2-3): 582-593, 04-05.

Kirshnan, Karthik, Debarshi K Nandy, and Manju Puri. (2015). "Does Financing Spur Small Business Productivity? Evidence from a Natural Experiment." The Review of Financial Studies 28(6): 1768-1809.

Lewbel, Arthur. (2012). "Using Heteroscedasticity to Identify and Estimate Mismeasured and Endogenous Regressor Models.” Journal of Business \& Economic Statistics 30(1): 6780. 
Lewis, Daniel J. (2019). "Robust Inference in Models Identified via Heteroskedasticity." Working Paper.

Nakamura, Emi, and Jón Steinsson. (2018). "High-frequency Identification of Monetary Nonneutrality: The Information Effect." The Quarterly Journal of Economics. 133(3): 12831330.

Nanda, Ramana, and Matthew Rhodes-Kropf. (2013). "Investment Cycles and Startup Innovation." Journal of Financial Economics. 110(2): 403-418

Rampini, Adriano A. (2004). "Entrepreneurial Activity, Risk, and the Business Cycle." Journal of Monetary Economics 51: 555-573

Rigobon, Roberto. (2003). "Identification Through Heteroskedasticity." The Review of Economics and Statistics. MIT Press, 85(4): 777-792

Rigobon, Roberto, and Brian Sack. (2003). "Measuring the Reaction of Monetary Policy to The Stock Market.” The Quarterly Journal of Economics 118(2): 639-669.

Rigobon, Roberto, and Brian Sack. (2004). "The Impact of Monetary Policy on Asset Prices." Journal of Monetary Economics 51(8): 1553-1575

Robb, Alicia and David Robinson. (2014). "The Capital Structure Decisions of New Firms." The Review of Financial Studies 27 (1): 153-179

Romer, Christina D., and David H. Romer. (1989). "Does Monetary Policy Matter? A New Test in the Spirit of Friedman and Schwartz," NBER Macroeconomics Annual 1989(4): 121-184.

Romer, Christina D., and David H. Romer. (2004). "A New Measure of Monetary Shocks: Derivation and Implications," The American Economic Review 94(4): 1055-1084.

Schumpeter, Joseph. (1942) Capitalism, Socialism, and Democracy.

Stuart, Toby and Olav Sorenson. (2003). "The Geography of Opportunity: Spatial Heterogeneity in Founding Rates and the Performance of Biotechnology Firms." Research Policy 32: 229-253.

Tenreyro, Silvana, and Gregory Thwaites. (2016). "Pushing on a String: US Monetary Policy Is Less Powerful in Recessions.” American Economic Journal: Macroeconomics 8(4): 43-74. 
Table 1: Growth Predictive Model - Logit Regression on IPO or Acquisition Within 6 Years

Equity Growth (IPO or Acquisition)

(1)

\section{Corporate Governance Measures}

Corporation $\quad 2.867$

$(0.0612)$

Name-Based Measures

Short Name

Eponymous

0.288

$(0.0163)$

Intellectual Property Measures

Trademark

(0.191)

Patent - Delaware Interaction

Patent Only

Delaware Only

Patent and Delaware

US CMP Clusters

Local

(0.0169)

Traded Resource Intensive

0.840

(0.0224)

Traded

1.048

(0.0200)

\section{US CMP High-Tech Clusters}

Biotechnology

E-Commerce

IT

Medical Devices

Semiconductors

1.539

$(0.220)$

\begin{tabular}{lc}
\hline$N$ & $26,969,231$ \\
pseudo $R^{2}$ & 0.184
\end{tabular}

We estimate a logit model with Growth as the dependent variable. Growth is a binary indicator equal to 1 if a firm achieves IPO or acquisition within 6 years and 0 otherwise. Growth is only defined for firms born in the cohorts from 1988 to 2010. This model forms the basis of our entrepreneurial quality estimates, which are the predicted values of the model. State fixed effects included; Incidence ratios reported; Robust standard errors in parentheses. 
Table 2: Summary Statistics

\begin{tabular}{lccc}
\hline \multicolumn{1}{c}{ Variable } & Obs & Mean & Std. Dev. \\
\hline 3-month T-Bill Rate & 6755 & 3.357 & 2.467 \\
& & & \\
Obs (Quantity of Startups) & 6755 & 5079.42 & 2270.76 \\
Average Quality of Startups & 6755 & .001 & 0 \\
RECPI (Quality-Adjusted Quantity of Startups) & 6755 & 2.793 & .919 \\
& & & \\
Ln(Obs) & 6755 & 8.416 & .507 \\
Ln(RECPI) & 6755 & .963 & .384 \\
\hline
\end{tabular}

Data for each weekday from January 1, 1988 to December 31, 2014, exlcuding weekends and public holidays. RECPI is the aggregate total entrepreneurship of companies founded in each day using the total number of firm registrations and the entrepreneurial quality methodology of Guzman and Stern (2019) to account for firm heterogeneity. Obs is the number of firms founded without adjusting for quality.

Table 3: Interest Rate Heteroskedasticity Regimes

\begin{tabular}{|c|c|c|}
\hline & Regime 1 (Low Variance) & Regime 2 (High Variance) \\
\hline Avg. of Variance of 3-month T-Bill Rate & 0.000843 & 0.0176 \\
\hline Avg. of Variance of $\operatorname{Ln}(\mathrm{RECPI})$ & 0.0479 & 0.0474 \\
\hline Avg. of Correlation T-Bill Rate \& Ln(RECPI) & -0.0252 & -0.0111 \\
\hline Avg. of Variance of $\operatorname{Ln}(\mathrm{Obs})$ & 0.0318 & 0.0324 \\
\hline Avg. of Correlation T-Bill Rate \& Ln(Obs) & -0.0655 & -0.0238 \\
\hline Percentage of All Observations & $82.01 \%$ & $17.99 \%$ \\
\hline
\end{tabular}

Table 4: Entrepreneurship Response Seven Days After Interest Rates Shock

\begin{tabular}{|c|c|c|c|c|}
\hline & $\begin{array}{c}\text { OLS } \\
\text { DV: } \operatorname{Ln}(\text { RECPI })_{\mathrm{t}+7} \\
(1)\end{array}$ & $\begin{array}{c}\text { Heteroskedasticity } \\
\text { DV: } \operatorname{Ln}(\text { RECPI })_{\mathrm{t}+7} \\
(2)\end{array}$ & $\begin{array}{c}\text { OLS } \\
\text { DV: } \operatorname{Ln}(\text { Obs })_{\mathrm{t}+7} \\
(3)\end{array}$ & $\begin{array}{c}\text { Heteroskedasticity } \\
\text { DV: } \operatorname{Ln}(\text { Obs })_{t+7} \\
(4)\end{array}$ \\
\hline 3-month T-Bill Rate & $\begin{array}{c}-0.0796 \\
(0.00143)\end{array}$ & $\begin{array}{c}-0.0316 \\
(0.0220)\end{array}$ & $\begin{array}{c}-0.141 \\
(0.00127)\end{array}$ & $\begin{array}{c}-0.0643 \\
(0.0411)\end{array}$ \\
\hline $95 \%$ C. I. & {$[-.082,-.077]$} & {$[-.075, .011]$} & {$[-.144,-.139]$} & {$[-.145, .016]$} \\
\hline
\end{tabular}

OLS columns represent the estimate of a simple OLS regression on the dependent variable. Heteroskedasticity columns use our preferred approach as described in Section IV. Standard errors from 500 bootstrapped samples in parentheses. Dependent variables are lagged seven days forward. RECPI is our measure of the quality-adjusted quantity of entrepreneurship while Obs is only the quantity. 
Table 5: Robustness Tests Across Time Periods

\begin{tabular}{lccc}
\hline & Jan, 1988 - Dec, 2014 & Mar, 1991 - Dec, 2007 & Jan, 1988 to Dec, 2014 \\
All Dates & All Dates & Excluding Recessions \\
& DV: Ln(RECPI $)_{\mathrm{t}+7}$ & DV: Ln(RECPI $)_{\mathrm{t}+7}$ & DV: Ln(RECPI $)_{\mathrm{t}+7}$ \\
& $(1)$ & $(2)$ & $(3)$ \\
\hline 3-month T-Bill Rate & -0.0316 & -0.0496 & -0.0474 \\
& $(0.0220)$ & $(0.0102)$ & $(0.00855)$ \\
\hline 95\% C. I. & {$[-.075, .011]$} & {$[-.07,-.03]$} & {$[-.064,-.031]$} \\
\hline Observations & 6747 & 4193 & 6038 \\
\hline
\end{tabular}

Dependent variable is $\log (\mathrm{RECPI})$ lagged seven days forwards for all models, estimated through the heteroskedasticity approach described in Section IV. Standard errors from 500 bootstrapped samples in parenthesis. Column (3) excludes the dates included in all NBER dated recessions, inclusive of the month the recession begins.

Table 6: Robustness Test Controlling for Economic Uncertainty

\begin{tabular}{|c|c|c|}
\hline & $\begin{array}{c}\text { Heteroskedasticity } \\
\text { DV: } \operatorname{Ln}(\text { Obs })_{t+7} \\
(1)\end{array}$ & $\begin{array}{c}\text { Heteroskedasticity } \\
\text { DV: } \operatorname{Ln}(\text { RECPI })_{t+7} \\
(2)\end{array}$ \\
\hline 3-month T-Bill Rate & $\begin{array}{l}-0.0523 \\
(0.0182)\end{array}$ & $\begin{array}{c}-0.0953 \\
(0.0293)\end{array}$ \\
\hline $95 \%$ C. I. & {$[-.088,-.017]$} & {$[-.153,-.038]$} \\
\hline \multicolumn{3}{|c|}{$\begin{array}{l}\text { Economic Policy Uncertainty Index (EPU) is a daily index that quantifies } \\
\text { newspaper coverage of policy-related economic uncertainty in the US (Baker } \\
\text { et al (2016)). Heteroskedasticity columns use our preferred approach as } \\
\text { described in Section IV and controls for Ln(EPU). Standard errors from } \\
500 \text { bootstrapped samples in parentheses. Dependent variables are lagged } \\
\text { seven days forward. }\end{array}$} \\
\hline
\end{tabular}

Table 7: Four Regimes

\begin{tabular}{lcccc}
\hline & Regime 1 & Regime 2 & Regime 3 & Regime 4 \\
\hline Avg. of Variance of 3-month T-Bill Rate & 0.000856 & $\mathbf{0 . 0 1 1 3}$ & $\mathbf{0 . 0 1 8 3}$ & 0.000694 \\
Avg. of Variance of Ln(RECPI) & 0.0163 & $\mathbf{0 . 3 3 2}$ & 0.0165 & $\mathbf{0 . 4 1 0}$ \\
Avg. of Correlation T-Bill Rate \& Ln(RECPI) & -0.0238 & 0.0596 & -0.0188 & -0.0419 \\
\hline Percantage of All Observations & $75.4 \%$ & $1.8 \%$ & $16.2 \%$ & $6.6 \%$ \\
\hline
\end{tabular}

Four different variance regimes are used to assess the heteroskedasticity in the data. We divide these regimes using the 10-day rolling variance of the 3 month T-Bill and the 10 day rolling variance of $\operatorname{Ln}(\mathrm{RECPI})$, both above and below the mean. Coefficients in bold indicate high variance regimes. 
Table 8: Four Regimes Estimates

\begin{tabular}{|c|c|c|c|c|c|c|c|}
\hline & $\begin{array}{c}\text { Main } \\
\text { DV: } \operatorname{Ln}(\text { RECPI })_{t+7} \\
(1)\end{array}$ & $\begin{array}{c}\text { Regime } 1,2 \\
\text { DV: } \operatorname{Ln}(\text { RECPI })_{t+7} \\
(2)\end{array}$ & $\begin{array}{c}\text { Regime } 1,3 \\
\text { DV: } \operatorname{Ln}(\text { RECPI })_{t+7} \\
(3)\end{array}$ & $\begin{array}{c}\text { Regime } 1,4 \\
\text { DV: } \operatorname{Ln}(\text { RECPI })_{t+7} \\
(4)\end{array}$ & $\begin{array}{c}\text { Regime } 2,3 \\
\text { DV: } \operatorname{Ln}(\text { RECPI })_{t+7} \\
(5)\end{array}$ & $\begin{array}{c}\text { Regime } 2,4 \\
\text { DV: } \operatorname{Ln}(\text { RECPI })_{t+7} \\
(6)\end{array}$ & $\begin{array}{c}\text { Regime } 3,4 \\
\text { DV: } \operatorname{Ln}(\mathrm{RECPI})_{\mathrm{t}+7} \\
(7)\end{array}$ \\
\hline 3-month T-Bill Rate & $\begin{array}{c}-0.0316 \\
(0.0220) \\
\end{array}$ & $\begin{array}{c}-0.0712 \\
(0.00698) \\
\end{array}$ & $\begin{array}{c}-0.0247 \\
(0.0126) \\
\end{array}$ & $\begin{array}{c}-0.0723 \\
(0.00411)\end{array}$ & $\begin{array}{c}-0.0930 \\
(0.00955)\end{array}$ & $\begin{array}{c}-0.0554 \\
(0.0840)\end{array}$ & $\begin{array}{c}-0.0993 \\
(0.00662)\end{array}$ \\
\hline $95 \%$ C. I. & {$[-.075, .011]$} & {$[-.085,-.058]$} & {$[-.049,0]$} & {$[-.08,-.064]$} & {$[-.112,-.07]$} & {$[-.22, .109]$} & {$[-.112,-.086]$} \\
\hline Observations & 6747 & 5072 & 6035 & 5431 & 1191 & 587 & 1550 \\
\hline
\end{tabular}

Dependent variable is $\log ($ RECPI) lagged seven days forwards for all models, estimated through the heteroskedasticity approach described in Section IV. Each column represents the estimate using two different regimes. Standard errors from 500 bootstrapped samples in parentheses. 
Figure 1: Comovements in Entrepreneurship (Ln(RECPI)) and Interest Rates (3-month T-Bill Rate)

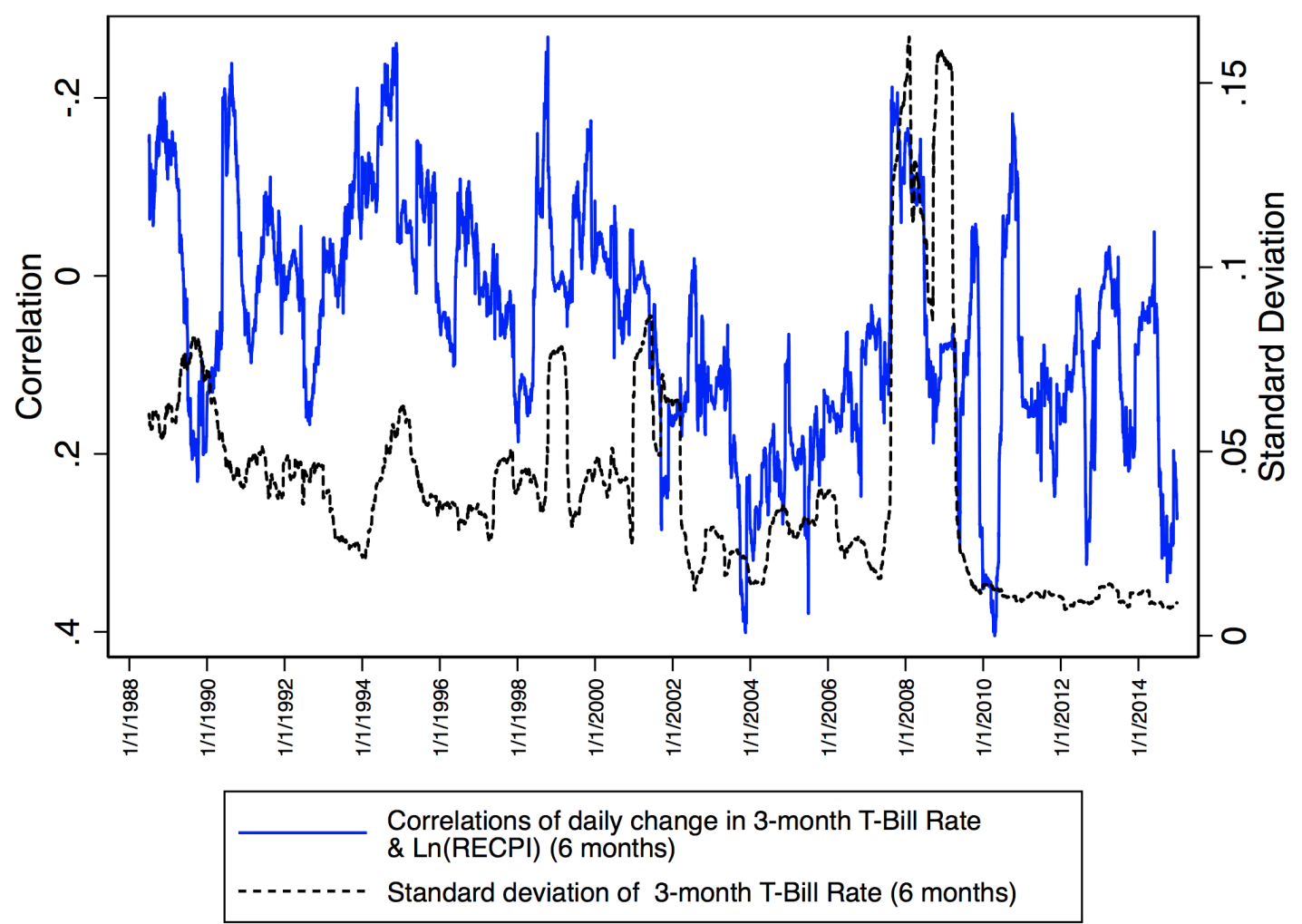

This figure shows the six-month rolling correlation between daily changes in the 3-month T-Bill Rate and daily changes in $\operatorname{Ln}(\mathrm{RECPI})$, with respect to the standard deviation of the 3-month T-Bill Rate, from July 1988 to December 2014. 
Figure 2: Simulated Response in Low and High Variance Regimes

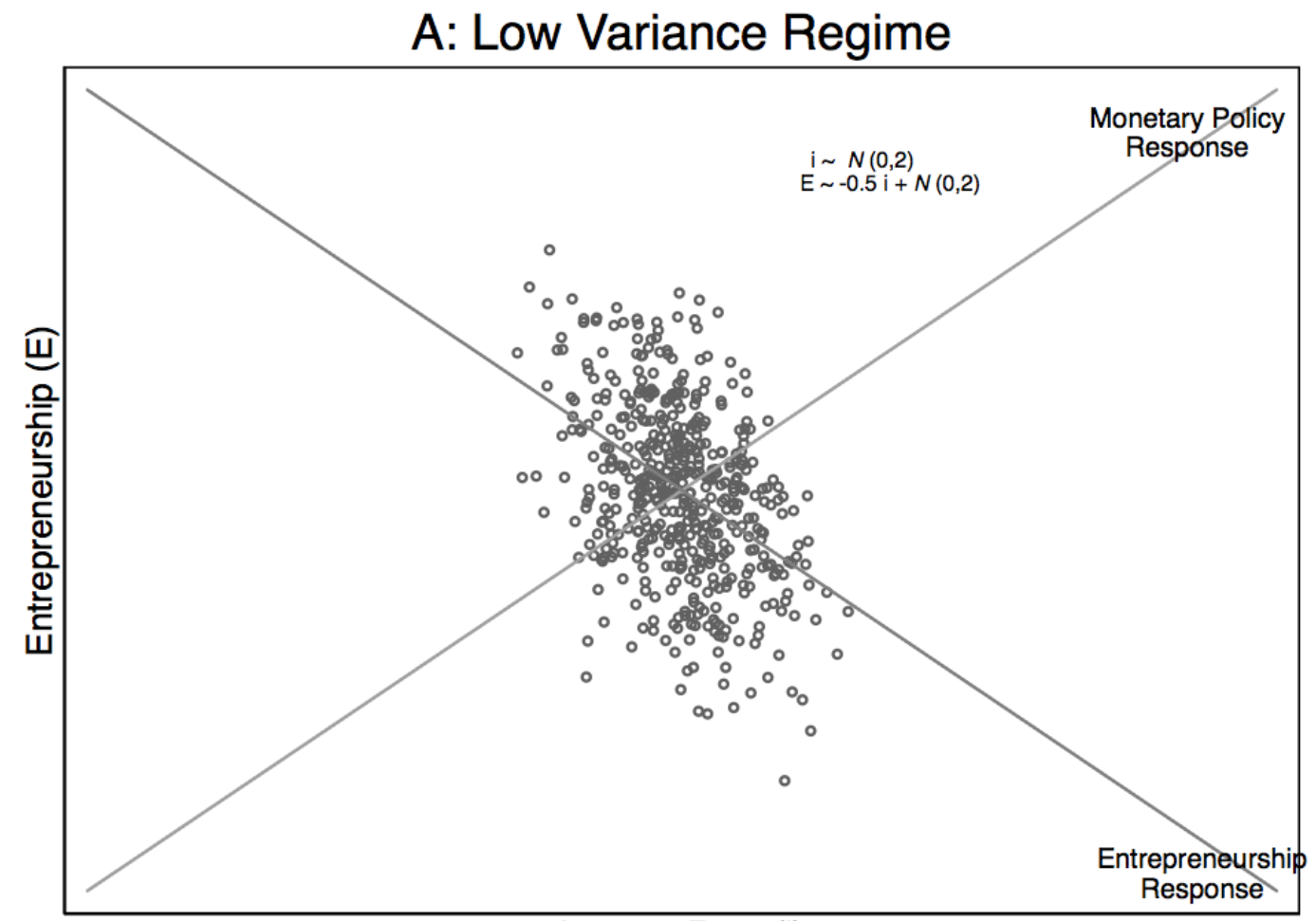

Interest Rate (i)

\section{B: High Variance Regime}

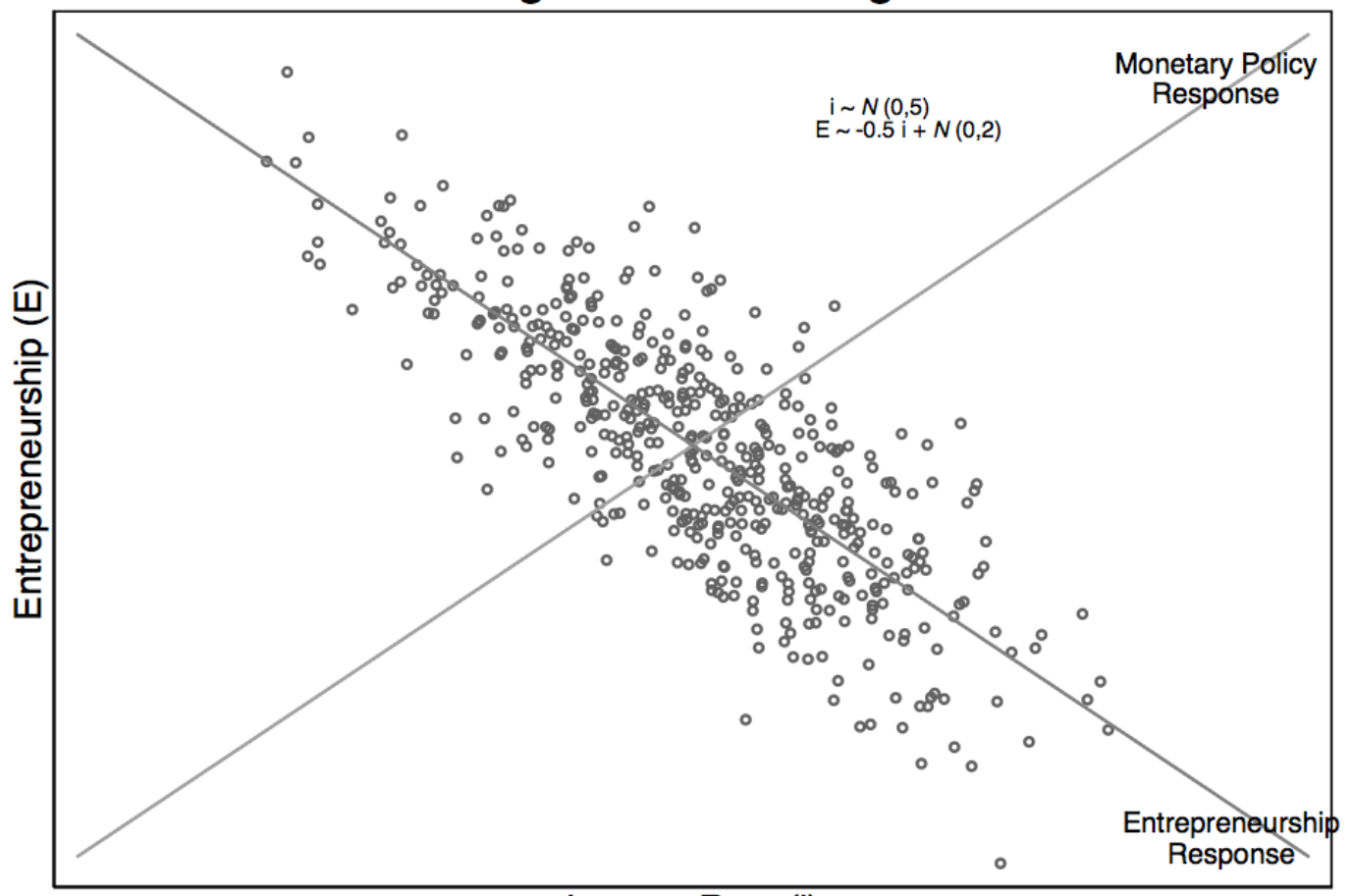

Interest Rate (i)

Figure 2A shows a simulation of interest rate and RECPI in a low variance regime, where interest rate (i) is generated from random draws of $N(0,2)$. Figure $2 \mathrm{~B}$ shows a simulation of interest rate and RECPI in a high variance regime, where interest rate (i) is generated from random draws of $N(0,5)$. In both graphs, RECPI is generated from random draws of $-0.5 \mathrm{i}+N(0,2)$. 
Figure 3: Histogram and Density Plots of $\beta$ for 500 Bootstrapped Samples
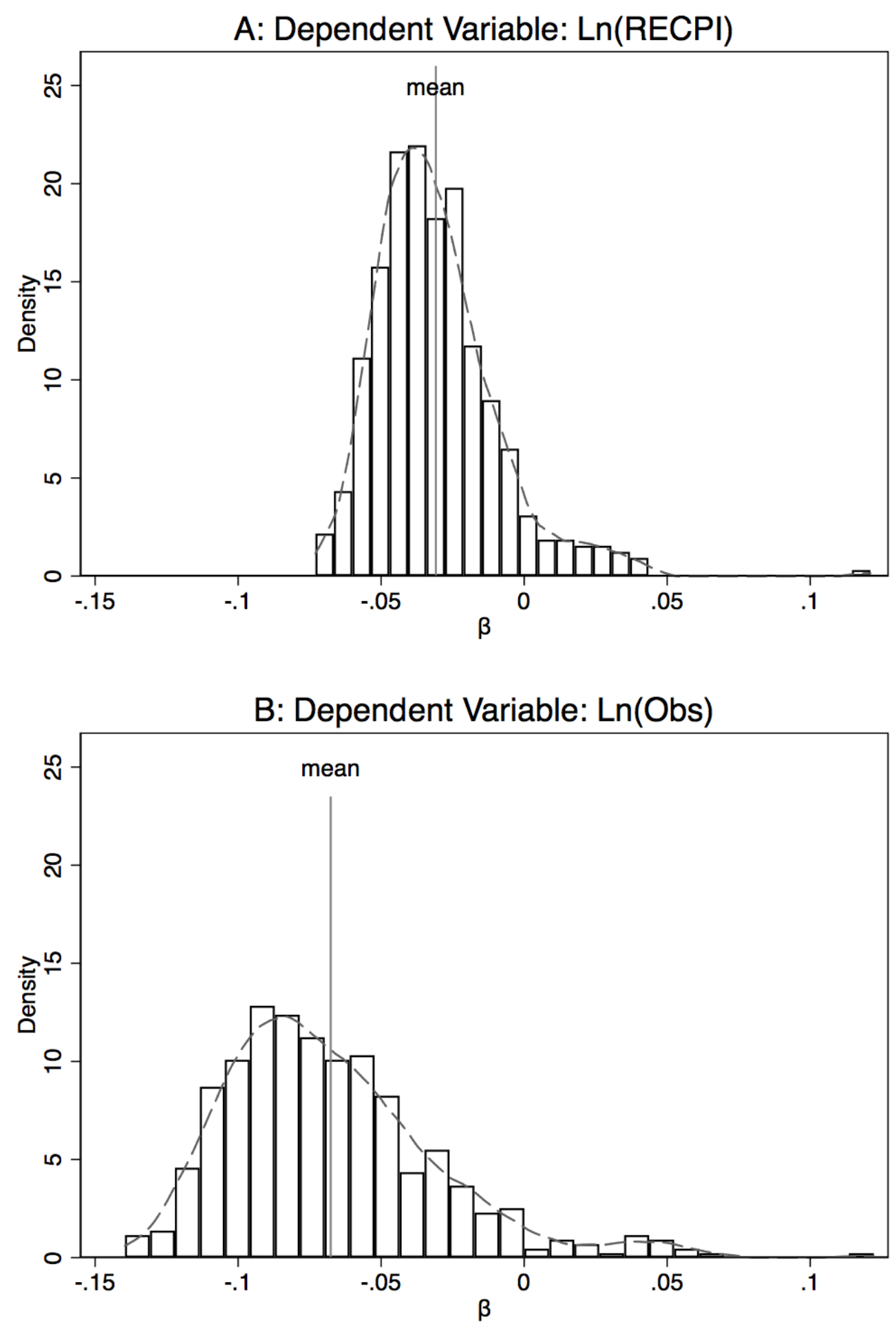

This figures shows the distributions of estimated impact of 3-month T-Bill Rate on $\operatorname{Ln}(\mathrm{RECPI})$ and $\operatorname{Ln}(\mathrm{Obs})$ for 500 bootstrapped samples. 
Figure 4: Impact of Interest Rate Shock on Entrepreneurship: Time Dynamics by Week

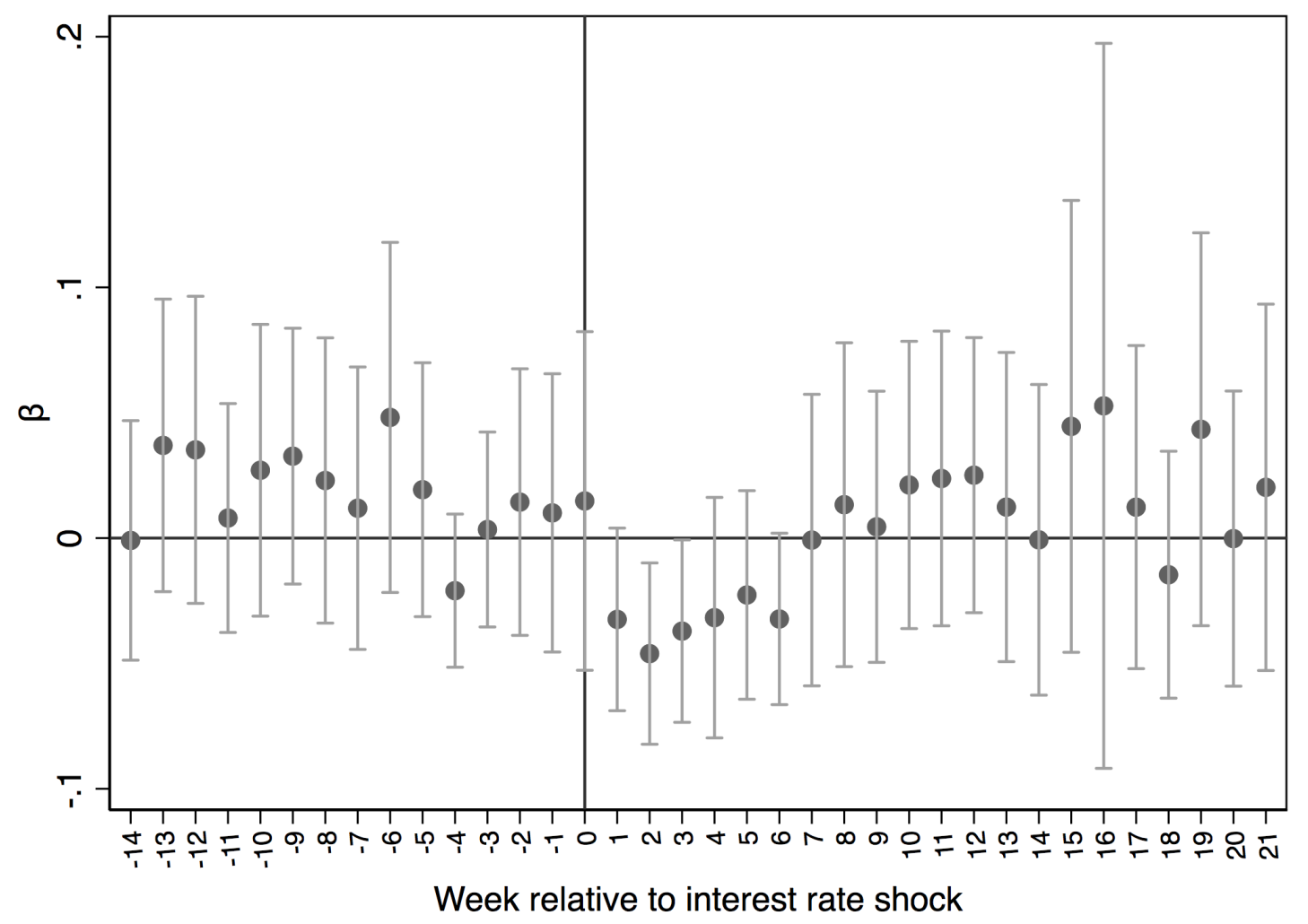

This figure reports the coefficient and 95-percent confidence interval of our main specification, using different lags of $\operatorname{Ln}(\mathrm{RECPI})$ as the outcome, increasing in seven day intervals from 14 weeks before the shock to 21 weeks after. 
Figure 5: Impact of Interest Rate Shock on Entrepreneurship: Daily Time Dynamics from -30 to +30 Days

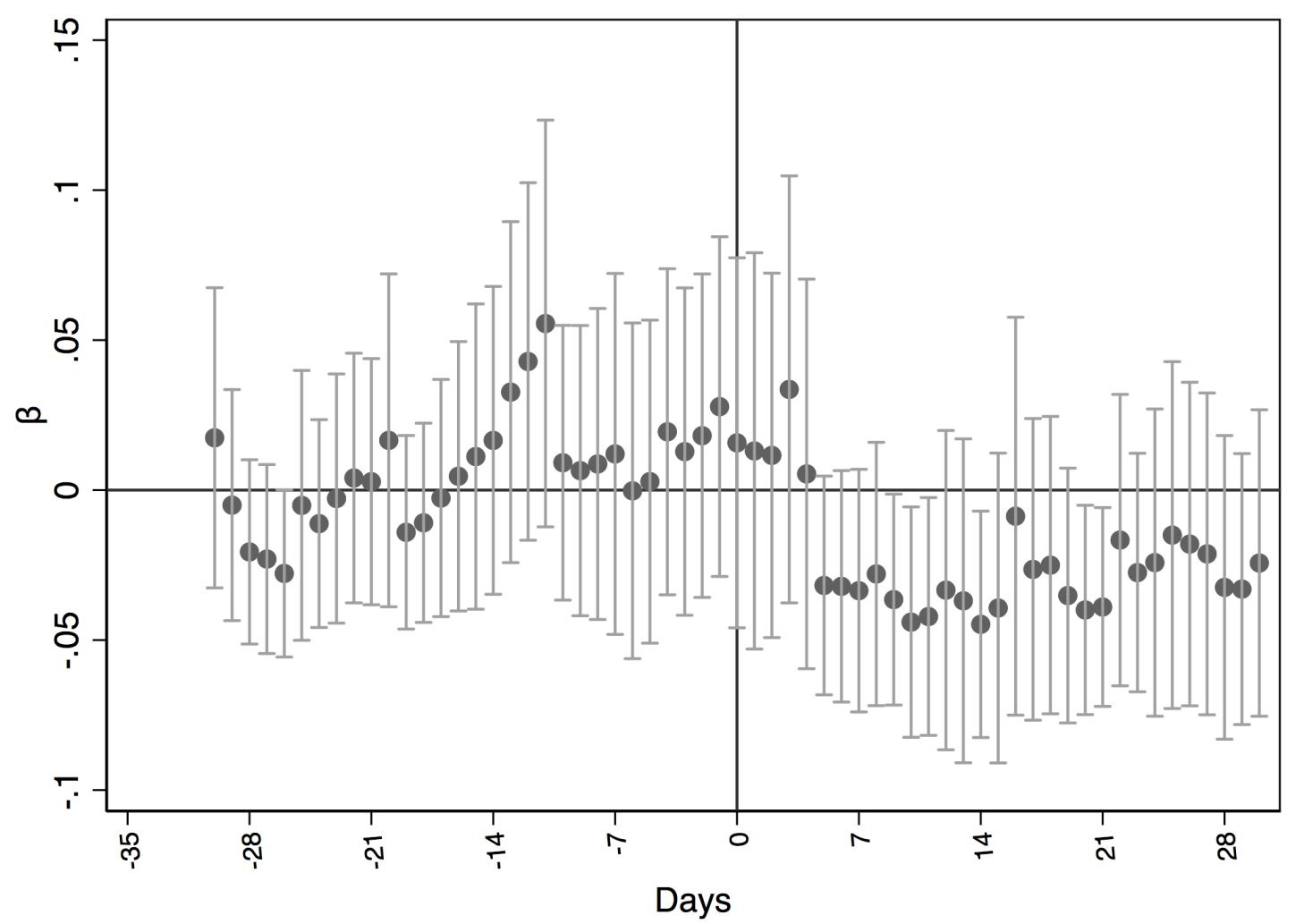

This figure reports the daily coefficient and 95-percent confidence interval of our main specification, using different lags of $\operatorname{Ln}(\mathrm{RECPI})$ as the outcome, from 30 days before to 30 days after the interest rate shock. 


\section{Appendix}

Table A1: Entrepreneurship Response Seven Days After Long-Term Interest Rates Shock

\begin{tabular}{|c|c|c|c|c|}
\hline & $\begin{array}{c}\text { 20-Year T-Bill } \\
\text { DV: } \operatorname{Ln}(\text { RECPI })_{t+7} \\
(1)\end{array}$ & $\begin{array}{c}\text { 20-Year T-Bill } \\
\text { DV: } \operatorname{Ln}(\text { Obs })_{t+7} \\
(2)\end{array}$ & $\begin{array}{c}\text { Spread } \\
\text { DV: } \operatorname{Ln}(\text { RECPI })_{t+7} \\
(3)\end{array}$ & $\begin{array}{c}\text { Spread } \\
\text { DV: } \operatorname{Ln}(\text { Obs })_{\mathrm{t}+7} \\
(4)\end{array}$ \\
\hline 3-month T-Bill Rate & $\begin{array}{c}0.0469 \\
(0.00545)\end{array}$ & $\begin{array}{c}0.0948 \\
(0.00597)\end{array}$ & $\begin{array}{c}-0.0468 \\
(0.00508)\end{array}$ & $\begin{array}{c}-0.0943 \\
(0.00571)\end{array}$ \\
\hline $95 \%$ C. I. & {$[-.058,-.036]$} & {$[-.106,-.083]$} & {$[-.057,-.037]$} & {$[-.106,-.083]$} \\
\hline
\end{tabular}


Figure A1: Impact of Interest Rate Shock on Entrepreneurship: 20-Year T-Bill Rate

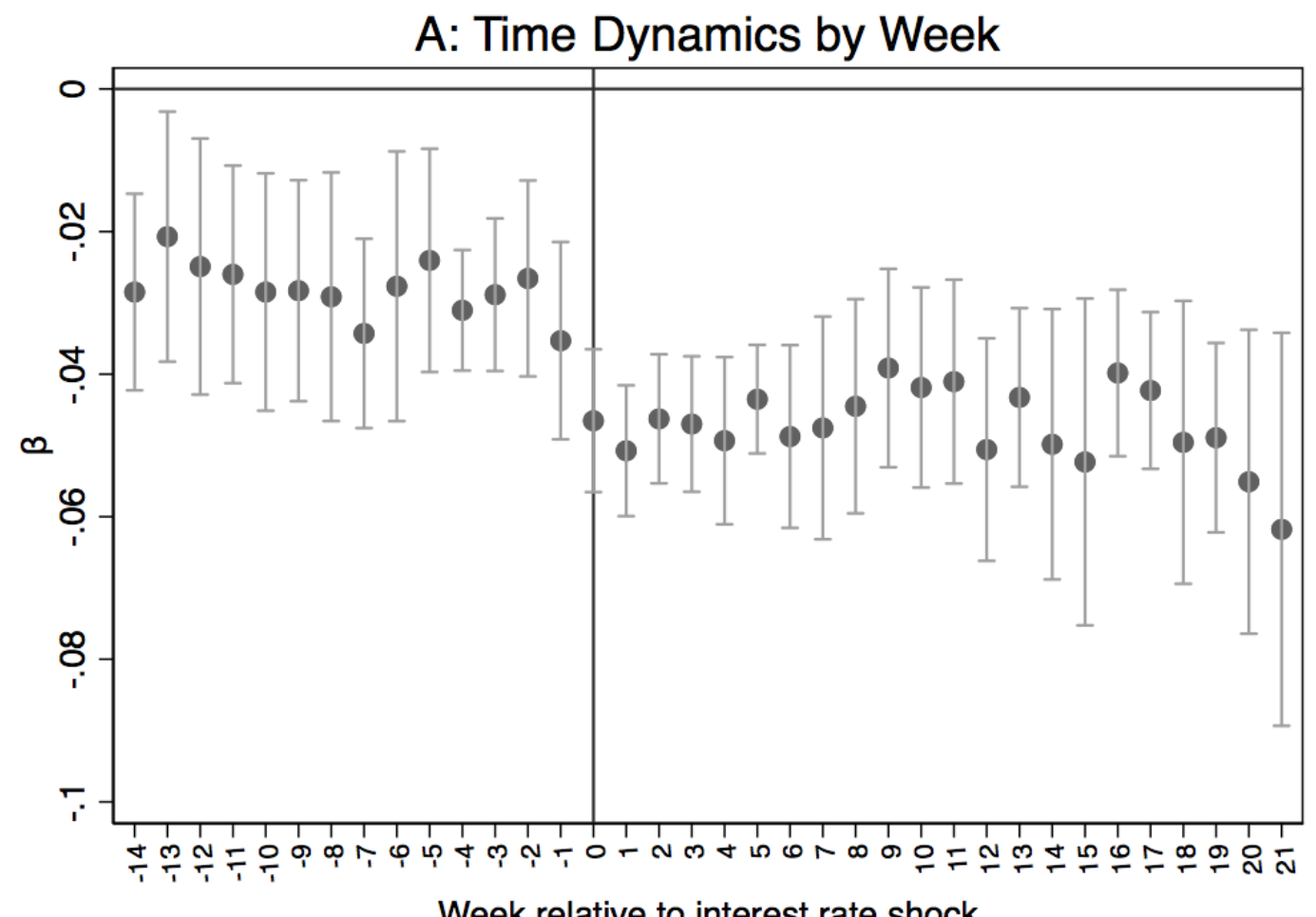

Week relative to interest rate shock

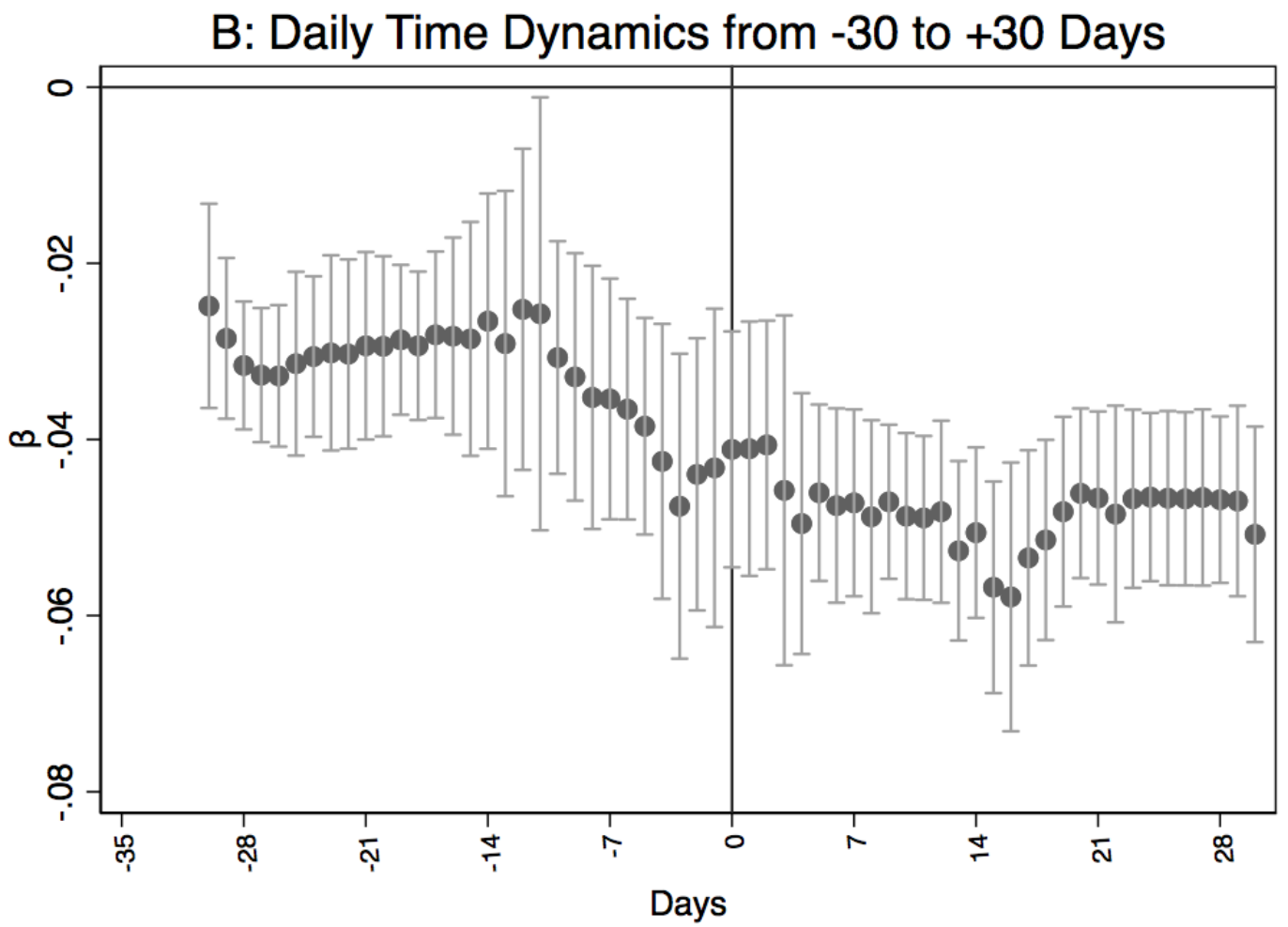

This figure reports the coefficient and 95-percent confidence interval of our main specification, using different lags of $\operatorname{Ln}(\mathrm{RECPI})$ as the outcome and the spread between the 20-year T-Bill and 3-month treasury yield as the interest rate; the weekly dynamic increases in seven day intervals from 14 weeks before the shock to 21 weeks after, and the daily dynamic increases from 30 days before to 30 days after the interest rate shock. 
Figure A2: Impact of Interest Rate Shock on Entrepreneurship: 20-Year-3 Month Treasury Yield Spread

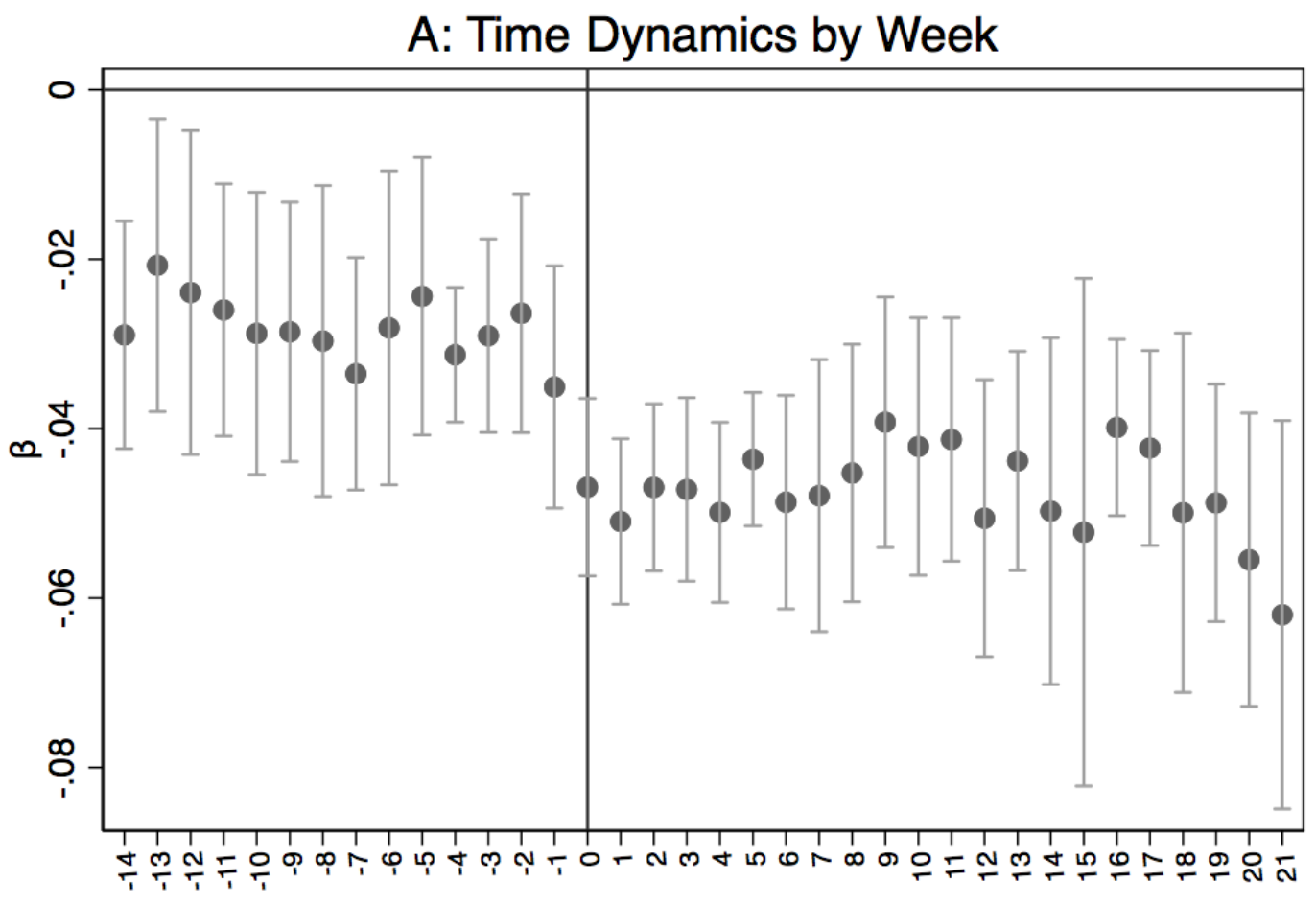

Week relative to interest rate shock

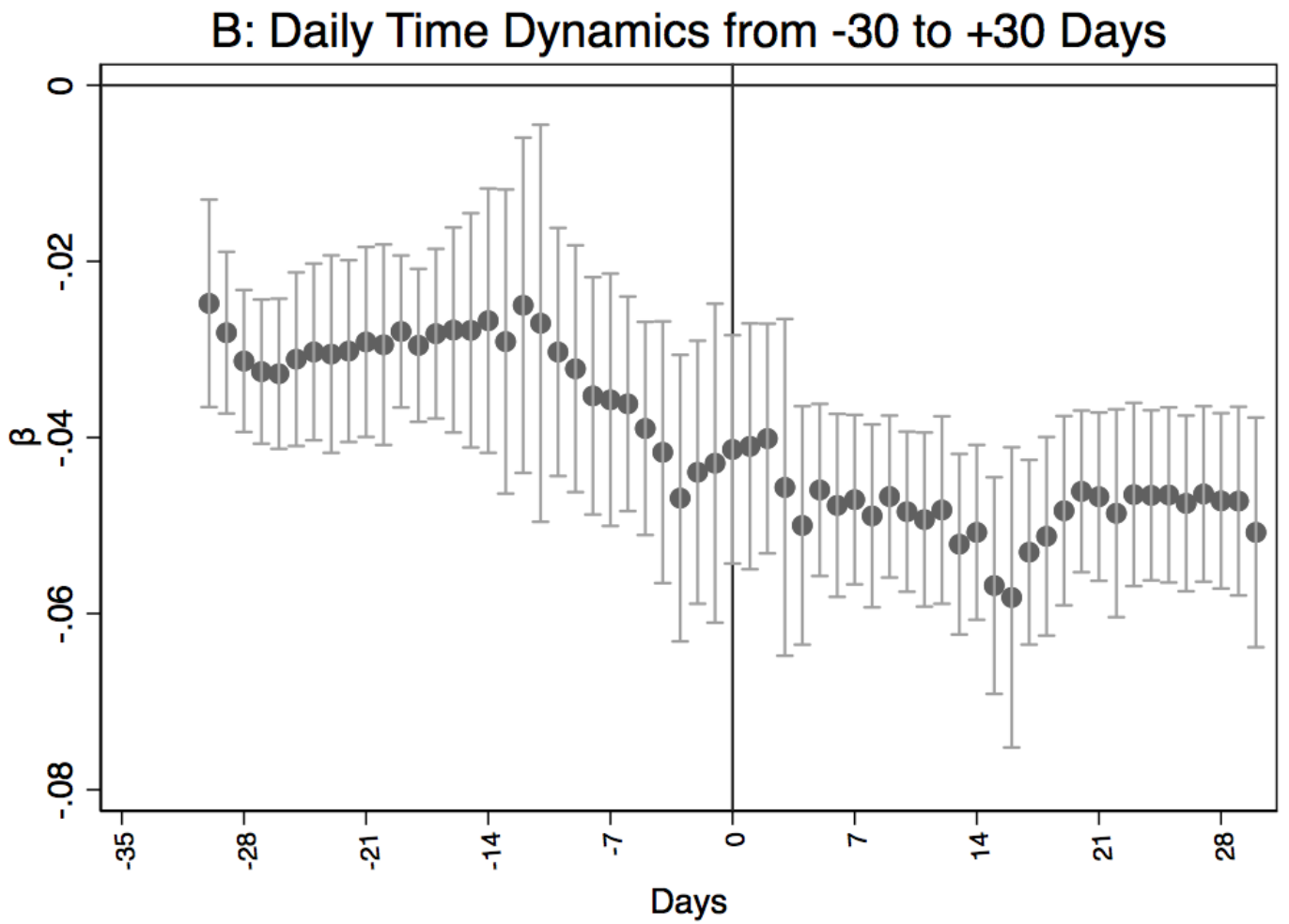

This figure reports the coefficient and 95-percent confidence interval of our main specification, using different lags of $\operatorname{Ln}(\mathrm{RECPI})$ as the outcome and the 20-year T-Bill as the interest rate; the weekly dynamic increases in seven day intervals from 14 weeks before the shock to 21 weeks after, and the daily dynamic increases from 30 days before to 30 days after the interest rate shock. 